Child-Father creative text-making at home with Crayons, iPad, Collage \& PC 


\section{Abstract}

This study examines how the properties of digital (an iPad app and PC software) and non-digital (collage and drawing) resources for children's text-making influence the creative expression of a three-year-old during collaborative text-making with her father at home. Particular attention was paid to the child's 'possibility thinking' (Craft, 2008) and engagement in 'what if scenarios', her father's support for this kind of creative expression and their joint creative collaboration as it unfolded during eight episodes of text-making. We used video transcripts analysed using thematic deductive analysis, supplemented with multimodal description of the processes and frequency measures for the individual and collaborative indicators of possibility thinking. The study makes three novel contributions. Firstly, it enriches our understanding of creativity as it is manifest in the home environment. Secondly, it focuses on father-child collaborative creativity, and demonstrates how adults in the home can influence the creative trajectories that children take in their text-making with different resources. Finally, the study shows how the features of specific text-making resources, both digital and nondigital, shape creative text-making as it unfolds. The differences in how creativity was manifest with the four resources indicate that each of the resources carry a distinct creative potential. This has implications for how we support early childhood creativity, both through the physical resources we provide for the activity and through the adult interactions that surround it, particularly in the home. 


\section{Introduction}

With the advent of new technologies, the range of children's text-making resources has widened, with digital text-making tools such as PC software and tablet apps now contributing to the spectrum of children's creative experiences at home and in school. While research has begun to shed light on the kinds of engagement digital text-making might support (Crescenzi et al., 2014; Carter-Ching et al., 2006), little is known about the extent to which digital text-making resources can contribute to children's creative expression and collaboration with others at home. This line of inquiry is important given that concerns have been raised about digital resources stifling rather than supporting children's creativity (Armstrong \& Casement, 2000; Levin \& Rosenquest, 2001; Olfman et al. 2003) and encouraging solitary use rather than shared creative interactions (House, 2012).

Previous research has shown that digital resources have the potential to shape creative expression in different ways. For example, tablet story-making applications (apps) that enable children to incorporate sounds or images taken from existing stimuli banks or the surrounding environments influence how children engage in text-making and the extent to which they adopt an exploratory approach and creative stance (Author et al., 2013; Williams et al., 2005). Similarly, text-making with PC-based software typically involves the presence of ready-made images that can be applied in texts (Burnett \& Myers, 2006). Consequently, it has been proposed that digital resources with openended design, as opposed to those with schematic and controlled templates, afford more opportunities for exploration and creativity (Author, 2014). McPake, Plowman \& Stephen (2014) investigated the role of digital toys and games used by pre-school children in the home context, focusing on the potential of these tools to expand 
children's early communicative and creative experiences, To date, however, the impact of specific design features of various resources on children's creative expression during text-making has not been systematically investigated. To understand how these and possible other features shape children's creative expression, there is a need to consider children's interactions with various resources in a particular context. There is also a need to explore the use of various resources within the wider environment in which they are used, supported by children's educators and caregivers (Anning, 2002, 2003; Burkitt et al., 2006). One activity where children together with adults frequently employ traditional as well as novel digital resources and which carries a potential for creativity is text-making.

\subsection{Text-making}

Text-making refers generally to various meaning-making activities which include artefacts such as drawings, collages, photographs and emergent writing (Pahl, 2003). More recently, these activities have been extended to meaning-making with iPad apps or computer software programmes. Text-making is a popular activity at home and in early years classrooms as it offers a rich repertoire for children to creatively express their identities, thoughts and feelings (Lemke, 2000; Mavers, 2007; Björkvall \& Engblom, 2010).

There are several resources which can support young children's text-making. Traditional resources include pens, paper, crayons and collage (Herr, 2012), each affording a multitude of options for children to express and shape their thinking and emotions (Ahn \& Filipenko, 2007; Heydon, 2011). With digital resources, creativity can be expressed through sound, image, colour, movement and simulation. In the early 2010s, iPad apps began to enter children's classrooms and homes, offering a range of apps designed to support children's text-making. For example, story-making apps 
where children can draw, personalize story-characters and add their own texts or sounds to stories, afford novel means for creative expression (Author, 2014). In addition to smartphone and tablet apps, PC-based software programmes offer unique text-making opportunities to children, for example through the addition of block colours, 'undo' facilities and ready-made images. Both apps and PC software provide children with multiple opportunities for changing and revising work in a low-risk environment, enabling creative activity to unfold in a non-linear fashion where ideas are combined, developed, edited, refined and presented in a parallel rather than sequential process (Facer \& Williamson, 2004).

The present study focuses on four text-making resources which are frequently used in young children's homes in the UK (Mayesky, 1998; Ofcom, 2013): crayons, collage, iPad app and PC-drawing software. All four resources offer the possibility to share, define and refine ideas in collaboration with others and multiple means for representing ideas, which could potentially afford creative collaborative engagement. The iPad app used in the present study was Our Story, which was developed at The Open University, UK for children of pre-school age. The app is freely available and enables users (children and parents) to take and organise photographs and add written captions or make audio recordings about these photographs. The PC software used was Tuxpaint, which is a free, award-winning drawing program for children aged 2 to 8.

\subsection{The theoretical framework adopted in the study}

Understanding the complex relationships between creative expression, textmaking resources and adult-child collaboration at home requires adopting a theory that would acknowledge the complex nexus of relationships between home and school textmaking opportunities, between those afforded by digital and non-digital resources and the sociocultural mediation of any creative expression in this network. In the study 
design and analysis reported here, we adopted a Vygotskian approach to learning and creativity, in which the cultural and social origin of artefacts and interactions are seen as central to activity as it unfolds (Vygotsky, 1962, 1978). Vygotsky's (1978) perspective stresses the dynamic dialectical interrelationship between the social and individual creative meaning-making; creativity is both an individual and social process (Moran \& John-Steiner, 2003). Creativity is a subjective and phenomenological experience, as described in the term 'perezhivanie' (Esteban-Guitart \& Moll, 2014). In addition, children's experiences are seen to be mediated through an interlinked network of influences, including tools and significant others such as children's peers, parents and other educators.

Vygotsky emphasised interrelationships rather than simple connections and studied creative processes 'in the making' (Moran \& Steiner, 2003, p. 68) - a method we adopted in the present study. Vygotsky (1962) placed great emphasis on the fact that children should be creators rather than consumers of texts, and that it is the process of engaging in creative imagination that is the key to unlocking this potential: 'It is not important what children create, but that they do create, that they exercise and implement their creative imagination' (Vygotsky, 2004, p.72).

Vygotsky's work is also relevant for a socio-cultural theoretical conceptualization of creativity, as it postulates that creativity, as an everyday act, is affected by the creator's interaction with his/her time and environment. Creativity is 'everywhere where 'human imagination combines, changes and creates anything new' (Vygotsky, 2004, p.10). Any product of creativity is thus the result of a socio-cultural process which occurs through collaboration, typically between a child and a more knowledgeable other (Vygotsky, 1964, 1967), through interaction with a variety of socio-cultural tools and everyday contexts. Applying Vygotsky's lens to the creative activity of text-making 
means that text-making is always influenced by the physical and social resources through which it is enacted (Vygotsky, 1966, 1978). Creativity within text-making is thus viewed as a transformative process during which various intellectual and physical resources are used to transform the 'known' into a novel form.

\subsection{Creativity}

Creativity is a multidimensional phenomenon which can be understood as a complex bricolage of processes in which specific resources are interconnected and synthesised in order to create original meanings (de Certeau, 1984; Russell \& Tyler, 2005). This includes a range of processes, including the ability to engage in play, to imaginatively approach traditional activities and to effectively integrate personal and social contributions to problem-solving (Jeffrey \& Craft, 2006; Craft, 2007). Adopting a sociocultural stance, Glavenau (2010) defined creative process as a 'complex socio-culturalpsychological process that, through working with "culturally-impregnated" materials within an intersubjective space, leads to the generation of artefacts that are evaluated as new and significant by one or more persons or communities at a given time' (p.11). In this study, we were keen to find out how these processes become manifest during the activity of text-making as well as the final products at the end of the activity. We focused on four different tools for text-making which, arguably, afford several opportunities for creative expression and collaboration. Considering the processes implicated in creative activities identified by Vygotsky $(1962,1978)$, we operationalized creative expression in terms of two key theoretical conceptualisations of creativity: possibility thinking and creative collaboration.

\subsection{Possibility thinking}

In 2000, Craft made the theoretical proposition that the core to creativity is possibility thinking and this conceptualisation was subsequently tested empirically 
(Burnard, Craft \& Cremin, 2006,; Cremin, Burnard \& Craft, 2006). The studies suggested that possibility thinking is 'the means by which questions are posed or puzzles surfaced' (Craft, 2008, p. 88); it includes 'problem solving as in a puzzle, finding alternative routes to a barrier, the posing of questions and the identification of problems and issues' (p.80, Jeffrey \& Craft, 2004) and foregrounds the notion of exploratory transitions from 'what is' to 'what might be' (Craft, 2000; 2002; 2011). This transition enables children to engage in imagining worlds and to take on different roles. The possibility of transition to 'what if' has parallels with other definitions of creativity and creative thinking, conceptualized as 'a break with habitual patterns of thought' (Robinson, 2001, p.135) and 'effective surprise' (Bruner, 1962). Children's possibility thinking becomes visible through several facets of behaviour, but mostly through play, immersion, innovation, posing questions, risk-taking, being imaginative, having self-determination and intentionality (Burnard, Craft \& Grainger, 2006; Craft, Cremin, Burnard, \& Chappell, 2008; Craft, 2010) .

Resources used in text-making have different affordances for shaping children's possibility thinking and these affordances are taken up by adults and children differently in home and in classroom settings (Kendrick, McKay, \& Moffatt, 2005; Pahl, 2009). The focus of past research has been predominantly on the characteristics of possibility thinking and the ways in which teachers nurture it (e.g., Craft, Cremin, Burnard, Dragovic, \& Chappell, 2012; Cremin, Chappell, \& Craft, 2012), with a range of resources in the classroom environment. In this respect, research has focused on the creative pedagogy of teachers. In a series of studies, Cremin et al. (2006) observed and documented the practices of creative teachers in UK schools and outlined the ways in which they provided opportunities for children's possibility thinking in the classroom. The authors identified three pedagogical strategies creative teachers employ to nurture 
possibility thinking in children's learning experiences: 1, the 'standing back' strategy in which the teachers discursively position themselves as agents of possibilities or 'what if' agents; 2, profiling learner agency, where teachers actively listen to children and engage in their activities and 3, creating time and space in which learners' ideas were taken seriously and their independence was nurtured (Craft, McConnon, \& Matthews, 2012). In addition, Eckhoff (2013) described the verbal support teachers used to guide and help explore children's creative disposition during classroom art-making.

Following our socio-cultural collaborative focus on creativity (Vygotsky, 1978; Glavenau, 2010), and the notion that creativity 'flourishes in open and purposeful environments in which both teachers and children share their passions and personalities' (Grainger, Goouch \& Lambirth, 2005, p.201), we were keen to investigate not only the child's individual creative expressions and the parent's support for it, but also their joint, collaborative creativity.

\subsection{Collaborative creativity}

Creative collaboration refers to the combined cognitive, affective, social and spiritual ways of making meaning (Craft \& Wegerif, 2006). In our focus on parent-child creative collaboration, we were keen to build on Glavenau's (2010) conceptualization of creativity as a fundamentally relational, intersubjective phenomenon as it has close parallels with Vygotsky's framework of meaning-making embedded within a social, historical and cultural environment.

To ascertain the extent of parent-child creative collaboration, we focused on their joint negotiation of ideas as well as joint physical manipulation of the text-making resources. We were specifically interested in the possible differences in parent-child creative collaboration with the four distinct text-making resources and their joint negotiation of ideas and physical manipulation of the resources. A similar focus was chosen by Chen 
(2010), who looked at children's collaborative strategies at home, using computer games with friends and acquaintances. Drawing on Crook's (1994) notion of negotiating shared understanding in collaborative episodes, Chen (2010) identified collaborative episodes as those in which children created a shared reference and formulated with others a mutual understanding based on that shared reference. This has synergies with Craft (2012) and her work on collaborative creativity in early childhood which stressed the role of narrative and its role as a driver of possibility thinking. We adopted Chen's (2010) notion for defining instances of creative collaboration and extended it to verbal and non-verbal negotiations of shared meaning as theorised by Craft $(2012,2013)$. In previous research, the focus has been predominantly on peer-to-peer creative collaboration (e.g., Vass et al., 2012; Eteläpelto \& Lahti, 2008) or joint creativity in specific community projects (e.g., Melles \& Howard, 2012) or online environments (e.g., Piller et al., 2005). We extend this work to focus on a joint parent-child interaction with both digital and non-digital resources, with a specific interest in sociocultural thinking and creativity, notably Vygotsky's ideas about complex interrelationships in collaborative activities and Craft's conceptualisation of possibility thinking.

\subsection{The present study}

This study aimed to provide insights into children's possibility thinking at home, as influenced by a set of digital and non-digital text-making resources. It also aimed to offer insights into how these text-making experiences are enacted in the form of creative collaborations between a child and her father in the home. In examining the complexities of individual and collaborative creative expressions, we were cognisant of specific developmental and environmental influences on the child's text-making practices (Brooker, 2002; Tomanovic, 2004; Frisch, 2006) and our processes of inquiry 
were therefore qualitative, underpinned by an interpretative paradigm which aims to characterise the key constituents of specific processes rather than seek causal explanations (Denzin \& Lincoln, 2000; Guba \& Lincoln, 1988). Possibility thinking and its relation to the features of the resources used, as well as the father's support provided during the child's engagement, was investigated by drawing on well-established theoretical traditions (Craft, 2001, 2011, 2012; Vygotsky, 1928, 1964, 1978). Episodes of text-making were analysed from a sociocultural perspective in which the focus rested on the comparison of influences of resources used in text-making, the parental contributions, and the interaction between the parent and child and the resources they used. The study addressed the following research questions: How do digital and nondigital resources shape a child's expression of, and her father's support for, possibility thinking? How do digital and non-digital resources support their joint collaborative creativity in the context of text-making?

\section{Methodology}

The study is a small-scale analysis of observations of a child and her father. The approach of analysing a single episode of adult-child interaction is a well-established method for inferring relations in an uncharted area and gaining an in-depth understanding of the processes involved (Calderwood, 1999; Stevenson, 2004; Kucirkova, Messer, Sheehy \& Flewitt, 2014; Mavers, 2007). In Mavers (2007) study for example, the researcher focused on one small set of interactions between a six-year-old girl and her uncle, which enabled the researcher show which forms, which meanings and which responses to the social context were orchestrated in an adult-child email exchange. Similarly, Ranker (2014) studied a single six-year-old's multimodal reading of 
a comic book to show how semiotic resources influence multimodal reading processes and how this might influence the child's meaning-making with multimodal texts.

We examined the occurrence of theoretically and empirically driven characteristics with four different resources. Deductive thematic analysis enabled us to discover and describe particular themes in the dataset. In addition, we used a multimodal approach (Kress, 1997) to reflect on particular interactions in fine detail and to maintain a focus on the multiple modes through which meaning is made in individual and collaborative text-making with traditional (Jewitt \& Kress, 2003; Kress, 2010) and digital resources (Flewitt, 2011).

\subsection{Study participants}

The study participants were a 3-year old girl and her father. The girl was the only child of the family. She attended an inner-city London nursery each weekday between $8 \mathrm{am}$ and $5.30 \mathrm{pm}$, where she was reported as making above-average levels of educational progress. Her father was 35 years-old at the time of the study and worked as a journalist. The pair frequently engaged in shared activities at home, including textmaking with various resources. The second author was the child's aunt and knew the family very well. This enabled observations to remain relaxed and for the researcher to respond with sensitivity to the needs of the child.

\subsection{Study design}

The study was conducted in the child's grandparents' home over the course of three months. For eight weekday evenings (Monday - Thursday), at roughly the same time and for roughly the same length of time (approximately 10-30 minutes that were convenient for the family), a text-making activity was initiated by the parent/carer with the child, using one of four text-making resources. We asked the father to use one of four text-making resources during each of our observations: white and coloured paper 
and coloured pencils; white and coloured paper and collage materials; the Tuxpaint software uploaded onto a laptop; and the Our Story app downloaded on an iPad2.

The second author of the study video-recorded the parent-child with a video camera mounted on a tripod, or via a handheld video camera, when the parent or child's movement during the activity made this necessary.

To build an estimate of the child's range of interaction patterns with the specific medium, the analysis of the text-making activities focused on two episodes of the parent-child interaction with all four resources, that is, eight observations in total. Each observation occurred on a different day, counterbalanced by order and the resource used. The study was approved by the Ethics Committee at The Open University, UK and followed the BERA's Revised Ethical Guidelines for Educational Research (2004) and NCRM's Guidelines for Visual Research. Pseudonyms were used to protect the identity of participants. The father's and girl's consent to participate was formally ascertained at the beginning of the study when the details of the study were explained (in broad terms to the girl and in writing and full detail to the father). Ongoing consent to participate was checked orally prior to each observation by the second researcher who was sensitive towards the girl's behaviour and relied on the father for gauging the girl's ongoing consent during periods of observation (see Flewitt, 2005).

\subsection{Documenting creativity}

To ascertain the extent of the child's possibility thinking with the different resources used at home, we focused on seven key features of possibility thinking in young children which had emerged from the study by Burnard et al. (2006) and are aligned with Craft's $(2000,2001)$ definition of children's possibility thinking: questionposing, play, immersion, innovation, risk-taking, being imaginative, self-determination and intentionality (see also Craft, 2001; Craft \& Chappell, 2009). 
To evaluate the father's support for the child's possibility thinking, we looked for evidence of the three behaviours described by Cremin et al. (2006) and later elaborated by Craft (2012) as indicative of adults' effective support for possibility thinking in classrooms: standing back, profiling learner's agency and creating time and space. For the parent standing back, we looked for signs of the father stopping and observing, or listening and noticing the nature of his daughter's engagement. For prioritising agency, we were interested in instances where the father would invite or provide opportunities for the child to make her own choices (within the constraints of the set activity). Lastly, for creating time and space, we perceived the interaction to be facilitating a more creative interaction when the father offered broad choices over what and how to engage with the text-making resources provided, when he took the child's ideas seriously, encouraged her independence, honoured her choices and flexibly handled the time it took to arrive at this stage.

For collaborative creativity between the parent and the child, we adopted the analysis method developed by Chen (2010), who identified episodes of collaborative creativity as those in which both partners participated in contributing to an idea, negotiated shared meanings and where there was evidence that when one partner initiated an idea, the other partner built on the idea afterwards (c.f. Crook, 1996, 1998). Chen (2010) extended Crook's work to the home learning context and parent-child drawing on computers. Similarly to Chen (2010), we considered episodes of joint contribution on the verbal level but also through parent-child joint manipulation of an artefact, which in the present study was one of the four text-making resources (Our Story app, crayons, collage or Tuxpaint on the PC).

\subsection{Data analysis}


A rough multimodal transcription of all video data was produced, noting down the parent's and child's nonverbal behaviour (including gestures, eye gaze, body orientation, posture and movements) as well as their speech, all alongside time stamps. This transcript facilitated a thematic deductive analysis in relation to possibility thinking and collaborative creativity literature, and was supplemented with a timesampled video analysis which provided frequency measures for the indicators of possibility thinking, adult support of possibility thinking and creative collaboration.

Samples of the video data were coded by both researchers according to the indicators based on previous literature and theoretical formulations of the creativity concepts (see Table 1). Where disagreements in coding occurred, the data was reviewed again, alongside additional time samples that enabled the disagreement to be resolved and a mutual decision to be reached.

Table 1 to be inserted about here

To explore the analytical themes further, we focused on a salient example of each theme 'in action', as it unfolded through the indicators described in Table 1. Each example that was selected constituted a frame of action (Scheflen, 1974; Kress et al, 2001) that foregrounded a particular theme e.g. the child's possibility thinking, through one or more indicator e.g. posing questions. The examples were both typical and powerful: typical in the sense that they described the ongoing interaction situation and powerful because they clearly demonstrated the particular category, that is, they represented illustrative examples of what was seen across the video data that was collected. The selected episodes ranged in length from two to five minutes (see Barbour, 2013). The selection of these examples followed a two-step procedure: First, we 
examined the transcripts and identified episodes in the parent-child interaction linked to different aspects of our creativity categories, building on the creative collaboration, expression and possibility thinking models. Second, key episodes for each category were selected and examined in more detail using the theoretical models outlined earlier in the paper. These were then added to Findings.

For the frequency estimates, we drew on other studies using time sampling during unstructured social interactions (Neumann et al., 2003). The researchers each independently produced a tally of the number of occurrences of behaviours characterising a specific facet of creativity (e.g., question posing as an indicator of child's possibility thinking) within a limited time interval of 22 minutes per each episode. These frequency estimates were first added up for the two episodes coded (two episodes per resource, i.e., 4x2) and then compared between the two researchers. Upon agreement of the episodes coded as indicative of the individual categories, the frequency estimates were averaged to yield a single value corresponding to each coded category. To allow comparisons among the different categories and different four resources, absolute scores were converted into frequency percentages, reported in Findings.

To ensure reliability and transparency within our work, we asked two independent coders to code a list of quotes from the transcripts with accompanying videos and asked them to assign them to a pre-established category. The inter-rater agreement was expressed as a Kappa statistic with 95\% confidence interval. We calculated coder reliability (the percentage of agreement) for all the categories coded between the first and second author of the study and between both authors and the two independent coders (combined scores). Overall inter-rater agreement between the two 
researchers was very high (kappa $=0.87)$ and between the researchers (combined scores) and the independent coders was high (kappa=0.79).

\title{
3. Findings
}

The first part of this section contains illustrative examples of parent-child interaction with each of the four text-making resources. We briefly describe the particular context and outline how these examples instantiate central concepts of creativity, in particular the child's possibility thinking, her father's support for it and their joint collaborative creativity. The second part presents results of a cross-context comparison, which relied on the frequency estimates of occurrence for the individual creativity indicators for each resource used.

\subsection{Crayons}

\author{
Insert Figure1 about here
}

The child was sitting on a chair next to her father; there was a pack of crayons and a blank piece of A4 paper in front of them on a wooden table. The conversation indicated that when it came to choosing the content of the drawing and the format of its depiction (e.g., by choosing the colours of the crayons used), the child wanted the end product to adhere to principles of visual realism. For instance, when depicting a girl's cardigan, she wanted it to be the same colour as the one she was wearing: 'Pink, it's pink' [The child looks down and tugs at her own cardigan]: 'Look it's pink, look, pink!' [the girl is pointing to the colour of her cardigan]. The restrained use of fantasy corresponded with her low risk taking behaviour and the difficulty she experienced in immersing herself in the activities of drawing and colouring. She repeatedly solicited her father's help at various 
stages and for various aspects of the drawing. For example, she asked her dad to help with the shapes of the final drawing as she couldn't achieve the kind of drawing she wished on her own: 'It was going round and around... can you do the round hoops for me? The round hoops and I'll do the heart'

The child's struggle to transition from the actual to an envisaged reality was also evident in her imperfect pronunciation of concepts she had heard in the context of drawing activities previously but could not depict herself. For instance, she was repeatedly bringing expectations about the shapes she thought needed to be included in the drawing, notably the oval shape which is difficult to draw at her young age but which she had heard about before, and wanted her father to draw for her: Child: 'Our heads are awvil [oval) heads' (...) : 'It's an awvil head remember'.

Although the father's intention was to let the girl take control of the activity, there was a recursive dynamic between the girl's expectation of how close the final product should match the perceived reality and her father managing this expectation with what could be achieved with the resources available. For instance, when the girl couldn't find a silver colour for drawing a necklace, she said: 'Oh it was silver... my necklace was silver'. Her father pointed to the grey crayon: 'So that's close to silver...grey'.

A large proportion of the second session was characterised by growing frustration on the part of the girl as, with the resources available and her drawing capabilities, she was unable to depict the shapes (e.g., oval and rectangle) and colours (e.g., silver and pink) as she had envisaged. The father seemed to have handled this conflict through a joint manipulation of the resources (e.g., handing over crayons or drawing parts of the image for her), rather than verbally negotiating ideas, and thus avoiding a potentially challenging discussion. 


\title{
3.2. Tuxpaint
}

\author{
Insert Figure2 about here
}

The child's creative engagement with Tuxpaint was demonstrated by several innovative suggestions for what could be achieved with the software, and there was clear evidence that she engaged in possibility thinking about what the final product could be, as seen in this example where the girl was experimenting with the bird stamp: 'That's a cuckoo', the girl says as she adds a bird stamp to the screen. The father acknowledges the drawing: 'Oh, a cuckoo'. The girl specifies: 'Three cuckoos'. After a pause she asks: 'Shall I do a million cuckoos?': 'You can', the father says, the girl laughs and clicks on the screen.

Before using the Tuxpaint software for the first time, the father explained to his daughter how the computer mouse worked and what the individual elements of the Tuxpaint software programme contained. He pointed out the possibility of choosing different colours, shapes and ready-made images such as stamps and stars. Although fully supportive of the girl's own ideas, the father was also making several verbal suggestions for software features the child could use to improve the format and content of the final artefact: 'Mmhmm... Why don't we choose a... stamp? Do you see the stamps there?' [The father points at the stamp icon]. 'Shall we see what different stamps there are?'. However, instead of jointly manipulating the resource, the father tended to make verbal suggestions which the child executed with aplomb, for example when it came to selecting the various shapes available: 'You did a line... and now we've selected a star shape... move around to select a different shape.. press again, press, woah'.

\subsection{Collage}


There was a rich variety of resources in this context, including large coloured sugar paper, smaller pieces of coloured card, old Christmas cards, playing cards, magazines, sticky tape, scissors and glue. The father and child were well-positioned at the table to freely access and use any of the resources.

Insert Figure3 about here

The activity opened up an area for several joint episodes of parent-child talk with both the father and the child discussing various innovative ideas of what the final product could be. These gave rise to parent-child exchanges and shared decision making around the creative use of the resources, as in the following exchange:

Child (cutting): 'Hey, I'm cutting a wiggly worm... I'm cutting a wiggly worm' Dad: 'Good job' 'So there's going to be a wiggly worm in our picture?' Child: 'Yeah, we're going to make the soiled'

Dad: 'So is our picture going to be under the earth?'

Child: 'Yep'

Dad: 'Wow, that's a good idea'

During such exchanges both the father and the child were highly immersed in the activity, exploring the wide choice and endless possibilities for the kinds of texts producible with the available resources. The discussion focused on hypothetical scenarios for what the final product might become and who it could be for. Audience awareness was also clear in the girl's intention of producing an artefact for display for other family members to look at and in the father's support in ensuring high quality of the final artefact. 
The father supported the child's independent thinking by making several suggestions for dividing the individual tasks and distributing the resources equally between him and his daughter. This seemed to encourage the child's agency and willingness to delegate some tasks to her father, who was ready to take them on: The father asks 'Is daddy going to do some cutting?' The father looks at the glue. The girl replies: 'Hey, you can cut this...' The girl picks up some paper, hands the paper to dad who takes it. 'Ok. What shape shall I make?', the father asks and picks up scissors. 'Some little squares' the girl answers.: 'Squares...' The father begins cutting; he looks up after cutting one square and the girl nods.

Episodes like these gave rise to collaborative creativity as they afforded simultaneous and joint manipulation of the text-making resources.

\section{4. iPad app: Our Story}

Figure 4 to be inserted about here

The use of the iPad app started in the living room but gradually moved around the house, as the girl was eager to use the iPad camera to take pictures of various objects in the house, including the washing machine in the bathroom or vacuum cleaner in the kitchen. The father closely followed her, giving her some tips on taking pictures and thus encouraging her independence but also adding ideas along the way: 'You can take as many as you like...but don't go so close to things because the camera can't see it because it's too dark, look that's it, you've got to... now try and get the baby seat, the car seat, see the car seat.' At times their roles switched and the father took photos while the girl made suggestions: 'Did you do it? Did you do it Daddy? Did you do this face?' [The father is taking picture of the girl as she holds a soft toy in front of her face.] 
When inserting pictures into the storyboard of the app, the father tended to dominate the interaction as he was supporting and structuring the girl's input: 'Now you do one... why don't you do one from today?' father asked the girl in one example, suggesting that she chooses one of the pictures taken on the day rather than a previously stored photograph on the 'camera roll' to which the child was drawn. Prior to this stage of the text-making however, there was a good balance of joint manipulation of the artefact and negotiation of the ideas and processes underpinning the text. The father and daughter seemed to have especially enjoyed the close physical proximity afforded by the iPad. Given that multiple touch would interfere with the story-making, they jointly manipulated the resource by, for example, the father holding the iPad while the girl swiped the pictures on the screen, or the girl holding the device when taking pictures and the father tilting the iPad cover so that it didn't obscure the iPad camera lens.

\subsection{Frequency estimates}

The frequency estimates of parent-child creativity in the four different contexts allowed us to better understand the patterns in the data and identify common and distinct features across the four contexts. Graph 1 illustrates the occurrence of the various creativity facets displayed by the child in the four contexts, followed by the father's support (Graph 2) and their joint collaborative creativity (Graph 3).

Figure 5, 6, 7 to be inserted about here

Cross-contextual comparison of the entire dataset indicated that the father and child engaged in more verbal collaborative creativity in the contexts with the two digital 
resources. In contrast, the crayons and collage contexts were characterised by the pair's joint manipulation of the resources. The collage context was characterised by the most balanced collaborative creativity-balanced in terms of the amount of verbal and physical collaboration in the text-making. As for the father's support of the child's possibility thinking in the four contexts, this was most noticeable in the Crayons context and least in the Tuxpaint context. Interestingly, most instances of the father's support in the form of creating time and space for possibility thinking occurred with the Collage resources. Drawing on the characteristics of individual possibility thinking and crosscontext comparison we found that the child was highly immersed in the Collage context and in comparison with all other contexts, showed most evidence for innovative and imaginative ideas. The child was least imaginative and playful in the Crayons context. She was most self-determined in the Tuxpaint and Crayons contexts and her risk-taking behaviour was most evident with the digital resources i.e., Tuxpaint and the iPad app.

\subsection{Final products}

Father-child use of the four text-making resources produced four different artefacts with distinct features and overall aesthetic impressions. For illustration purposes, we selected one finished artefact per context in our analysis. The four final products were chosen pragmatically, with the aim to illustrate the variety of final products achieved in each of the four contexts. In the crayons context, the child was visibly not satisfied with the final product and wanted to scribble over it so that no one could see it and 'laugh at it'. At the end of the observation, she told the researcher: 'We're scribbling on it because it's going to make everyone laugh and I'm scribbling on it'. The collage activity, in contrast, led to an artefact the child was proud to show to the researcher and wanted to continue working on after the observation finished. The final 
product here was a three-dimensional "compost" with earthworm species and trees and sky above it. With the iPad app, the final product was a multimedia story, with text written by the father and audio spoken by the child and pictures taken by both of them, as they walked around the house. The child was keen to share this with the researcher and replay the audio recordings of her own voice. With the Tuxpaint software the final product was an image of a "million cuckoos" as the child added many stamps over splashes of various colours on the screen. The father was somewhat more conscious than the child of the creative value of this final product, making sure immediately after the activity that the work was saved on the laptop. It would be difficult to establish the creative value of each of the final products but a cross-context comparison clearly indicates a difference in the size, colours, texture, design, weight and possibility for sharing the product with others. All of these characteristics were influenced by the creative processes of collaborative text-making that we analysed-as discussed next.

Figure 8 to be inserted about here

\section{Discussion}

Researchers typically focus on the creative potential of individuals (e.g., Pickard, 1990) or groups of individuals in different contexts (e.g., Cheung et al., 2004) but less so on comparing how specific resources support creative interactions and the relationships that evolve with and around these resources. In our conceptualisation of creativity, we drew on Craft's (2000, 2001) and Cremin's (2006) work concerned with creativity in interaction between adults and children and adopted Vygotsky's theory $(1964,1967,1978)$ to understand the potential of this dynamic process as it unfolds in 
four different contexts, supported by four different meditational tools (Vygotsky, 1967; Thorne, 2005).

More specifically, we aimed to examine the ways and extent to which four different text-making resources influence parent-child possibility thinking and creative collaboration at home. The results showed that the child displayed different facets of possibility thinking with the different resources and also, that her father provided different opportunities for possibility thinking depending on the resources used. Consequently, their collaborative creativity was differently distributed in the four contexts and involved distinct manifestations and levels of the physical manipulation of the artefact and/or the joint discussion of ideas. When comparing the relative frequency of occurrence of facets of possibility thinking in the four contexts, we found that with the iPad app and Tuxpaint software, there were many instances of risk-taking by the child. Furthermore, she was highly immersed and innovative in the Collage context but self-determined and intentional in the Crayons context. The father supported his daughter's agency and independent manipulation most when using the non-digital resources. For collaborative creativity, the digital resources supported mostly verbal negotiation of ideas, while in the Crayons context the dyad collaborated predominantly on the artefactual level through joint manipulation of the resources. Only the Collage context afforded a balanced creative collaboration on both a physical and verbal level. A detailed look at the transcripts provided more insight into these differences and in this section, we discuss the results in relation to the theoretical connection between socio-cultural relevance and creativity (Vygotsky, 1978). We also use a Vygotskian theoretical framework to comment on the different facets of creativity observed in the four contexts. 
Vygotsky's theory foregrounds the socio-cultural influence in creative processes, and this was apparent to a different degree in each of the four contexts. For example in the Crayons context, the girl seemed to have been intentionally choosing colours and shapes to achieve a drawing she had identified a priori, based on previous drawings typical of her socio-cultural context. Bruner (1986) considered how children access and entertain multiple imaginative worlds and we showed how the girl's possible world in this context was constrained as she had a fixed idea of what a girl's depicted body should look like and was reluctant to accept her father's suggestions for 'what if' possibilities of different representations. This was different with Tuxpaint and the collage materials where the influence of socio-cultural norms and values was less dominant. Heydon (2011) argues that children are constrained by schema regardless of the materials and resources they use in their text-making. Our data offer a perhaps more nuanced interpretation as it seems to be the case that children's creativity is influenced by different schema depending on the resource used, for instance we saw less evidence of the girl following a pre-established schemas of producing a text in the Tuxpaint and Collage context where there seem to be fewer societal expectations of how a final product might look.

The socio-cultural influence on creativity was evident also in the parent-child joint manipulation of the artefacts: in the Collage and Crayons contexts, the pair negotiated the use of the resources and jointly explored their creative potential but in the Tuxpaint and iPad contexts, the father tended to restrict the child's free exploration of the resource. Vygotsky (1978) theorised that society places various constraints on children's expression of creativity but did not specify how this may differ according to adult support and the resources that are used. We found that the father offered different support for the child's possibility thinking with the digital and non-digital resources, 
corresponding to the often-cited expectation that children require more guidance and safeguarding with the use of digital resources (e.g., Becta, 2006) but less with nondigital resources, such as crayons and collage (e.g., Koster, 2014).

For the child, however, it wasn't the digital versus non-digital distinction that mattered most, but rather particular characteristics of the resources, which appeared to influence her imagination, immersion and playfulness in the four contexts. She was less immersed and playful in the Crayons activity but more so during Tuxpaint text-making, even though the Tuxpaint software offers several templates and ready-made images, which could be seen as possibly restricting immersion and imagination. It seemed to be the case that the mental schema the child brought to the activity - the pervasive sense that drawings should follow 'visual realism' (Duncum, 2009) was harder to subvert and 'remix' (Lankshear \& Knobel, 2006) than the ready-made templates that appeared in the digital context. This was also visible with the iPad text-making activity where the girl's expression of possibility thinking was only at a particular stage of the activity: she gave free rein to her fantasy at the picture-taking stage, where her ideas of what could be photographed were novel and original and did not conform to any particular picturetaking practice.

Vygotsky (1978) emphasised the dialectical relationships between mediational tools and culture and the notion that socio-cultural values are embedded not only in the activities supported by these tools but also in the ideas and creative products these tools mediate. It follows that the extent to which the different resources supported flexibility (e.g., the possibility to delete and start an action afresh) were influential in the extent to which the child immersed herself in the activity, but also in the support her father offered for free creative exploration and the overall perceived value of the created object. While with crayons an unwanted scribble cannot be easily removed from 
the page, this is relatively easy with the iPad or Tuxpaint resource (with a simple tap or click an action can be undone). In the Collage activity, a 'mistake' can be repaired with adding more layers or colours to the artefact. We saw several instances in which the collaborative creativity between parent and child remained more on the verbal level (e.g., in the Tuxpaint context) but was more hands-on when both partners were allowed to freely experiment and make 'mistakes' (e.g., Collage context). Glăveanu (2010, p.91) points out that there is a difference in how 'members of different communities assess the creativity of one and the same artifact' and we extend this observation to the same community (parent and child) who associated different values with their creative products according to the possibility for revision in creating the final artefact.

Another important characteristic of the four contexts is the extent to which they offered free or restrained access points for joint manipulation. This is relevant in light of Vygotsky's (1967) premise that more complex knowledge and experiential environments provide greater potential for creativity than simple ones. Each of the four resources had a different experiential potential. For instance, the Tuxpaint software was fairly restricted with a non-interactive screen and mouse-manipulation, while the Collage context was characterised by a multiplicity of access points for both parent and child. Perhaps then, not surprisingly, in the Tuxpaint context, the father contributed only very little to the final product while in the Collage and Crayons context, he was more 'hands-on' as he could access various resources (pencils or collage materials) to contribute to the final product. Conversely, the child showed a 'bricolage-like creativity', or what Baker and Nelson (2005, p.333) describe as engagement where people 'create something from nothing' or from 'applying combinations of the resources at hand to new problems and opportunities' in the Collage and Tuxpaint contexts.

\subsection{Study limitations}


When interpreting the study findings, it should be borne in mind that there might have been other aspects of creativity which we did not cover in the present study but which might have influenced the patterns observed here. For example the parent's and the child's personality characteristics, and overall language, literacy and cognitive abilities also contributed to the process (Amabile, 1983).

It should also be acknowledged that the study does not have a longitudinal design which limits the conclusions drawn. It could be that over time, the child would become more familiar with the resources, notably with the digital resources, and that the parent-child interaction dynamics would have evolved.

Another important caveat is that the resources studied here were specifically chosen for their potential to support unrestricted text-making. Notably in relation to the digital resources, the Tuxpaint software and the Our Story app were both described as open-ended digital resources by their producers, designed to support young children's creative text-making. It is not known how the parent-child creativity expression would be influenced with different digital resources where the possibility for open-ended content is often restricted (Author, 2013).

We recognise that the resources selected for analysis in this study are not universally accessible to all children in the UK. However, children's exposure to technology, including mobile technologies and laptops, has been recognised as increasing in UK families (Ofcom, 2014). Although the study focused on an iPad and a laptop, the software programmes we used (Our Story and Tuxpaint) are available for free via any tablets (Android devices) or laptops.

As researchers, we are aware of our own preconceptions, which, invariably, shape qualitative research (cf Cohen \& Crabtree, 2008). Our work in the area of digital text-making in early years would have shaped the interpretations, though we perceive 
our expertise in this area as advantageous, affording a more detailed insight into the observed events than would have been achieved by researchers whose background is not in digital literacy. Given the close relationship between the second author and the study participants, we adopted a reflexive research process which reveals the researcher's position throughout the research process and acknowledges her role in the study context. The data collection procedures and data analysis were developed and fully discussed between the authors. It is our view that the aunt-niece relationship allowed a richer interpretation of the observed events.

\subsection{Study implications}

Our findings do not support the concern that digital resources stifle children's creativity (Armstrong \& Casement, 2000; Levin \& Rosenquest, 2001; Olfman et al. 2003; House, 2012). Rather, this study suggests that there is a complex interrelationship between the properties of digital and non-digital text-making resources which impact on distinct facets of a child's creative expression and parents' support. Instead of drawing a firm distinction between digital and non-digital resources, it would be more accurate to recognise the complex, interlinked relationship between specific facets of creativity and the properties and socio-cultural norms associated with different textmaking resources, all of which impact on the products and processes of parent-child creativity in a different way. As Vygotsky (2004, p.31) put it, the process of individual and collaborative creativity is 'very complex and depends on a whole series of extremely diverse factors' and we have shown that these factors include the characteristics of digital and non-digital resources used for text-making and the parentchild individual and joint negotiation of their creative potential. Craft (2012) argues for the importance of dialogue and encourages practitioners to take an active and co- 
participative role in nurturing creativity with young children in the digital era. We add to this suggestion that collaborative creativity plays out differently with digital and nondigital resources and a fine-grained, theoretically informed analysis of parent-child textmaking with old and new resources can provide insights into the specific facets of their potential for nurturing its various expressions. 
References

Author, 2013

Author et al., 2013

Author, 2014

Ahn, J., \& Filipenko, M. (2007) Narrative, imaginary play, art, and self: Intersecting worlds. Early Childhood Education Journal, 34(4), 279-289.

Amabile, T. M. (1983). The social psychology of creativity: A componential conceptualization. Journal of personality and social psychology, 45(2), 357.

Baker, T., \& Nelson, R. E. (2005). Creating something from nothing: Resource construction through entrepreneurial bricolage. Administrative science quarterly, 50(3), 329-366.

Barbour, R. (2013). Introducing qualitative research: a student's guide. London:Sage.

Basadur, M., \& Hausdorf, P.A. (1996). Measuring divergent thinking attitudes related to creative problem solving and innovation management. Creative Research Journal, 9(1), 21-32.

BECTA (2006) British Educational Communications and Technology Agency Safeguarding children in a digital world, Coventry, UK, Retrieved from: http://www.wisekids.org.uk/BECTA\%20Publications/safeguarding_children_ls cb_strategy.pdf

Björkvall, A., \& Engblom, C. (2010). Young children's exploration of semiotic resources during unofficial computer activities in the classroom. Journal of Early Childhood Literacy, 10(3), 271-293.

Braun, V., \& Clarke, V. (2006). Using thematic analysis in psychology.Qualitative research in psychology, 3(2), 77-101.

Bruner, J. (1962) "The Conditons of Creativity." In Contemporary Aproaches to Creative 
Thinking, edited by H. Gruber, G. Terel, and M. Wertheimer. New York: Atherton,

Burkitt, E., Jolley, R., \& Rose, S. (2010). The attitudes and practices that shape children's drawing experience at home and at school. International Journal of Art \& Design Education, 29(3), 257-270.

Burnard, P., Craft, A. and Grainger, T. (2006), Possibility Thinking, International Journal of Early Years Education, 14(3) 243-262

Calderwood, P. E. (1999). Emily's Song: A case study of egocentric speech. Early Childhood Education Journal, 27(1), 21-27.

Cheung, P. C., Lau, S., Chan, D. W., \& Wu, W. Y. (2004). Creative potential of school children in Hong Kong: Norms of the Wallach-Kogan Creativity Tests and their implications. Creativity Research Journal, 16(1), 69-78.

Cohen, D. J., \& Crabtree, B. F. (2008). Evaluative criteria for qualitative research in health care: controversies and recommendations. The Annals of Family Medicine, 6(4), 331-339.

Craft, A. (2000) Creativity Across the Primary Curriculum, Framing and developing practice. London: Routledge.

Craft, A. (2002) Creativity and Early Years Education London: Continuum.

Craft, A. (2001) Little c creativity. In Craft,Jeffrey and Leibling (eds) (2001) Creativity in Education, London: Continuum.

Craft, A. (2007), Possibility Thinking in the Early Years and Primary Classroom, in Tan, A.G. (Ed), Singapore Handbook of Creativity. Singapore: World Scientific Publishing. 
Craft, A., Cremin, T., Burnard, P., Chappell, K. (2008) Possibility Thinking, in Craft, A., Cremin, T. and Burnard, P. (Eds) (2008), Creative Learning 3-11 and How We Document It. Stoke-on-Trent: Trentham Books.

Craft, A., \& Chappell, K. (2009), Fostering Possibility through Co-researching Creative Movement with 7-11 year olds, Blenkinsop, S. \& Egan, K. (Eds), The Imagination in Education: Extending Boundaries of Theory and Practice. Cambridge Scholars Publishing

Craft, A. (2010), Possibility Thinking and Fostering Creativity with Wisdom: opportunities and constraints in an English context. In Bhegetto, R., Kaufman, J. (Eds). Nurturing Creativity in the Classroom. Cambridge: Cambridge University Press, 289-312

Craft, A. (2011) Creativity and education futures. Stoke On Trent: Trentham.

Craft, A. (2012). Childhood in a digital age: creative challenges for educational futures, London Review of Education, (10)2, 173-190.

Craft, A., McConnon, L., \& Matthews, A. (2012). Child-initiated play and professional creativity: Enabling four-year-olds' possibility thinking. Thinking Skills and Creativity, 7(1), 48-61.

Craft, A., Cremin, T., Burnard, P., Dragovic, T., Chappell, K. (2012) Possibility Thinking: culminative studies of an evidence-based concept driving creativity?, Education 3-1, DOI:10.1080/03004279.2012.6566 Link: http://dx.doi.org/10.1080/03004279.2012.656671

Craft, A. (2013). Childhood, Possibility Thinking and Education Futures, International Journal of Educational Research 61, 126-134 
Cremin, T., Burnard, P., \& Craft, A. (2006). Pedagogy and possibility thinking in the early years. Thinking skills and creativity, 1(2), 108-119.

Cremin, T., Chappell, K., Craft, A. (2012), Reciprocity between narrative, questioning and imagination in the early and primary years. Thinking Skills and Creativity 9 (2013) 135- 151. DOI: http://dx.doi.org/10.1016/j.tsc.2012.11.003

Crook, C. (1996). Computers and the collaborative experience of learning. London: Psychology Press.

Crook, C. (1998). Children as computer users: The case of collaborative learning. Computers \& Education, 30(3), 237-247.

Duncum, P. (2009). Visual culture in art education, circa 2009. Visual Arts Research, 6475.

Eckhoff, A. (2013) Conversational Pedagogy: Exploring Interactions Between a Teaching Artist and Young Learners During Visual Arts Experiences. Early Childhood Education Journal, 41(5), 365-372.

Esteban-Guitart, M., \& Moll, L. C. (2014). Funds of Identity: A new concept based on the Funds of Knowledge approach. Culture \& Psychology, 20(1), 31-48.

Eteläpelto, A., \& Lahti, J. (2008). The resources and obstacles of creative collaboration in a long-term learning community. Thinking skills and creativity,3(3), 226-240.

Facer, K., \& Williamson, B. (2004). Designing educational technologies with users. NESTA Futurelab.

Flewitt, R. (2005). Conducting research with young children: Some ethical considerations. Early Child Development and Care, 175(6), 553-565.

Flewitt, R. (2011). Bringing ethnography to a multimodal investigation of early literacy in a digital age. Qualitative Research, 11(3), 293-310. 
Frisch, N. S. (2006). Drawing in preschools: A didactic experience. International Journal of Art \& Design Education, 25(1), 74-85.

Jeffrey, B., \& Craft, A. (2004). Teaching creatively and teaching for creativity: distinctions and relationships. Educational studies, 30(1), 77-87.

Jeffrey, B. and Craft, A. (2006), Creative Learning and Possibility Thinking. In Jeffrey, B. (Ed), Creative Learning Practices: European Experiences. London: The Tufnell Press.

Glăveanu, V. P. (2010). Paradigms in the study of creativity: Introducing the perspective of cultural psychology. New ideas in psychology, 28(1), 79-93.

Grainger, T. Goouch, K. \& Lambirth, A. (2005) Creativity and Writing: Developing Voice and Verve in the Classroom, London: Routledge.

Hermansson, C. (2013). Nomadic writing: exploring processes of writing in early childhood education. Dissertation | Karlstad University Studies, Faculty of Arts and Social Sciences, Department of Educational Studies,SE-651 88 Karlstad, Sweden.

Herr, J. (2012). Creative resources for the early childhood classroom. Cengage Learning. Heydon, R. M. (2011) Multimodal communication and identities options in an intergenerational art class. Journal of Early Childhood Research, 10 (1), 51-69.

Hocevar, D., \& Bachelor, P. (1989). A taxonomy and critique of measurement used in the study of creativity. In J.A. Glover, R.R. Ronning, \& C.R. Reynolds Eds.),Handbook of creativity (pp.53-75). New York: Plenum Press.

House, R. (2012). The inappropriateness of ICT in early childhood: Arguments from philosophy, pedagogy, and developmental research. Contemporary debates in childhood education and development, 105-120. 
Kendrick, M., McKay, R., \& Moffatt, L. (2005). The Portrayal of Self in Children Drawings of Home, School, and Community Literacies. Portraits of Literacy Across Families, Communities, and Schools, Mahwah (New Jersey), Lawrence Erlbaum Associates, 185-204.

Kress, G. (2011). Discourse Analysis and Education: A Multimodal Social Semiotic Approach In R. Rogers (Ed.), An introduction to critical discourse analysis in education 2nd Edn. (pp. 205-226), New York, Routledge.

Koster, J. (2014). Growing artists: Teaching the arts to young children. Wadsworth: Cengage Learning.

Neumann, C. G., Bwibo, N. O., Murphy, S. P., Sigman, M., Whaley, S., Allen, L. H., ... \& Demment, M. W. (2003). Animal source foods improve dietary quality, micronutrient status, growth and cognitive function in Kenyan school children: background, study design and baseline findings. Journal of Nutrition, 133(11), 3941S-3949

Lankshear, C. \& Knobel, M. (2006) New Literacies: Everyday Practices and Classroom Learning. Maidenhead: Open University Press..

Lemke, J. L. (2000). Across the scales of time: Artifacts, activities, and meanings in ecosocial systems. Mind, culture, and activity, 7(4), 273-290.

Mavers, D. (2007). Semiotic resourcefulness: A young child's email exchange as design. Journal of Early Childhood Literacy, 7(2), 155-176.

Mayesky, M. (1998). Creative activities for young children. (6th ed.). Albany, NY: Delmar. McPake, J., Plowman, L., \& Stephen, C. (2013). Pre - school children creating and communicating with digital technologies in the home. British Journal of Educational Technology, 44(3), 421-431. 
Melles, G., \& Howard, Z. (2012). Empower Me-Social Design Innovation for Homeless Families: Collective Design Creativity. In DS 73-2 Proceedings of the 2nd International conference on Design Creativity Volume 2.

Moran, S. \& John-Steiner, V (2003). Creativity in the making. In Moran, S. \& John-Steiner, V., \& Sawyer, (Eds) Creativity and development, Oxford: Oxford University Press, 61-90.

Ofcom, (2013)Children and Parents: Media Use and Attitudes Report, Available online from: http://stakeholders.ofcom.org.uk/binaries/research/medialiteracy/october-2013/research070ct2013.pdf

Ofcom, (2014) Children and Parents: Media Use and Attitudes Report, Available online from: http://stakeholders.ofcom.org.uk/market-data-research/other/researchpublications/childrens/children-parents-oct-14/

Olfman, S. (Ed.). (2003). All Work and No Play--: How Educational Reforms are Harming Our Preschoolers. Greenwood Publishing Group.

Pahl, K. (2009). Interactions, intersections and improvisations: Studying the multimodal texts and classroom talk of six-to seven-year-olds. Journal of Early Childhood Literacy, 9(2), 188-210.

Pickard, E. (1990). Toward a theory of creative potential. The Journal of Creative Behavior, 24(1), 1-9.

Piller, F., Schubert, P., Koch, M., \& Möslein, K. (2005). Overcoming Mass Confusion: Collaborative Customer Co-Design in Online Communities. Journal of Computer-Mediated Communication, 10(4).

Ranker, J. (2014) The role of semiotic resource complexes in emergent multimodal reading processes: Insights from a young student's reading of a comic book [online]. Australian Journal of Language and Literacy, 37, 3, 151-160 
Robson, S. (2014). The Analysing Children's Creative Thinking framework: development of an observation-led approach to identifying and analysing young children's creative thinking. British Educational Research Journal, 40(1), 121-134.

Russell, R., \& Tyler, M. (2005). Branding and Bricolage Gender, consumption and transition. Childhood, 12(2), 221-237.

Schirmacher, R. (1906) talking with young children about their art. Young Children, 41, 3-7.

Stevenson, R. B. (2004). Constructing knowledge of educational practices from case studies. Environmental Education Research, 10(1), 39-51.

Strauss, A., \& Corbin, J. (1990). Basics of qualitative research: Grounded theory procedures and techniques. Newbury Park, CA: Sage.

Strauss, A., \& Corbin, J. (1994). Grounded theory methodology-An overview. In N. K. Denzin \& Y. S. Lincoln (Eds.) Handbook of qualitative research (pp. 273-285). Thousand Oaks, CA: Sage.

Strauss, A., \& Corbin, J. (1998). Basics of qualitative research: Techniques for developing grounded theory (2nd ed.). Thousand Oaks, CA: Sage

Thorne, S. L. (2005). Epistemology, politics, and ethics in sociocultural theory. The Modern Language Journal, 89(3), 393-409.

Van Leeuwen, T. (2006). Towards a semiotics of typography. Information Design Journal, 14(2), 139-155.

Vass, E., Littleton, K., Miell, D., \& Jones, A. (2008). The discourse of collaborative creative writing: Peer collaboration as a context for mutual inspiration. Thinking Skills and Creativity, 3(3), 192-202.

Vygotsky, L. (1928). Pedology of the school child. Oxford: Second Moscow State University Press. 
Vygotsky, L. (1964). Thought and language. Annals of Dyslexia, 14(1), 97-98.

Vygotsky, L. S. (1966). Development of higher mental functions. In A. R. L. Leontyev (Ed.), Psychological Research in the USSR. Moscow: Progress Publishers.

Vygotsky, L. S. (1967). Play and its role in the mental development of the child. Journal of Russian and East European Psychology, 5(3), 6-18.

Vygotsky, L. S. (1978). Mind in society: The development of higher psychological processes. Cambridge, MA: Harvard University Press.

Vygotsky, L. S. (1981). The instrumental method in psychology. The concept of activity in Soviet psychology, 135-143.

Vygotsky, L. S. (1987). The collected works of LS Vygotsky: Problems of general psychology, including the volume Thinking and speech. Rieber RW, Carton AS, (Eds, translated by Minick N), Problems of general psychology (pp. 39-285). New York: Plenum (Original work published 1934).

Vygotsky, L. S. (2004). Imagination and creativity in childhood. Journal of Russian and east European psychology, 42(1), 7-97. 
Table1: Facets of possibility thinking coded in the study

\section{CHILD possibility thinking- coded categories}

Immersion and play

Includes episodes of pretence and socio-dramatic play, where the child is fully

immersed in the activity and pretends to take on new roles

Innovation and being imaginative

Includes episodes where the child is suggesting and producing new ideas (with the artifacts she interacts with), these ideas need to be both original and of value, they should show flexibility and evidence of creating 'new knowledge'

Risk taking

Includes episodes where the child displays a willingness to take risks, and willingness to learn from mistakes (cf Robson, 2014). It also refers to episodes where the child embraces new ideas and integrates them into her activity.

Self-determination and intentionality

Includes episodes where the child shows willingness to tackle obstacles, displays selfesteem, self-efficacy and resilience if challenged. Intentionality includes episodes where the child persists with her ideas and manages uncertainty brought about by new challenges. 
Table 2: Coded categories for father's creativity expression

\begin{tabular}{|l|}
\hline FATHER: facilitating possibility thinking \\
standing back' strategy \\
parent is a 'what if agent'- he asks questions and poses \\
challenges and then steps back; \\
Profiling learner agency \\
providing multiple opportunities in which the children could \\
initiate their own activities or make their own choices within a \\
loosely framed activity \\
\hline Creating time and space \\
Provides open access to a wide range of learning resources and \\
broad choices over what and how to engage; \\
the existence of an enriched, mutually-owned space
\end{tabular}


Figure1: Crayons

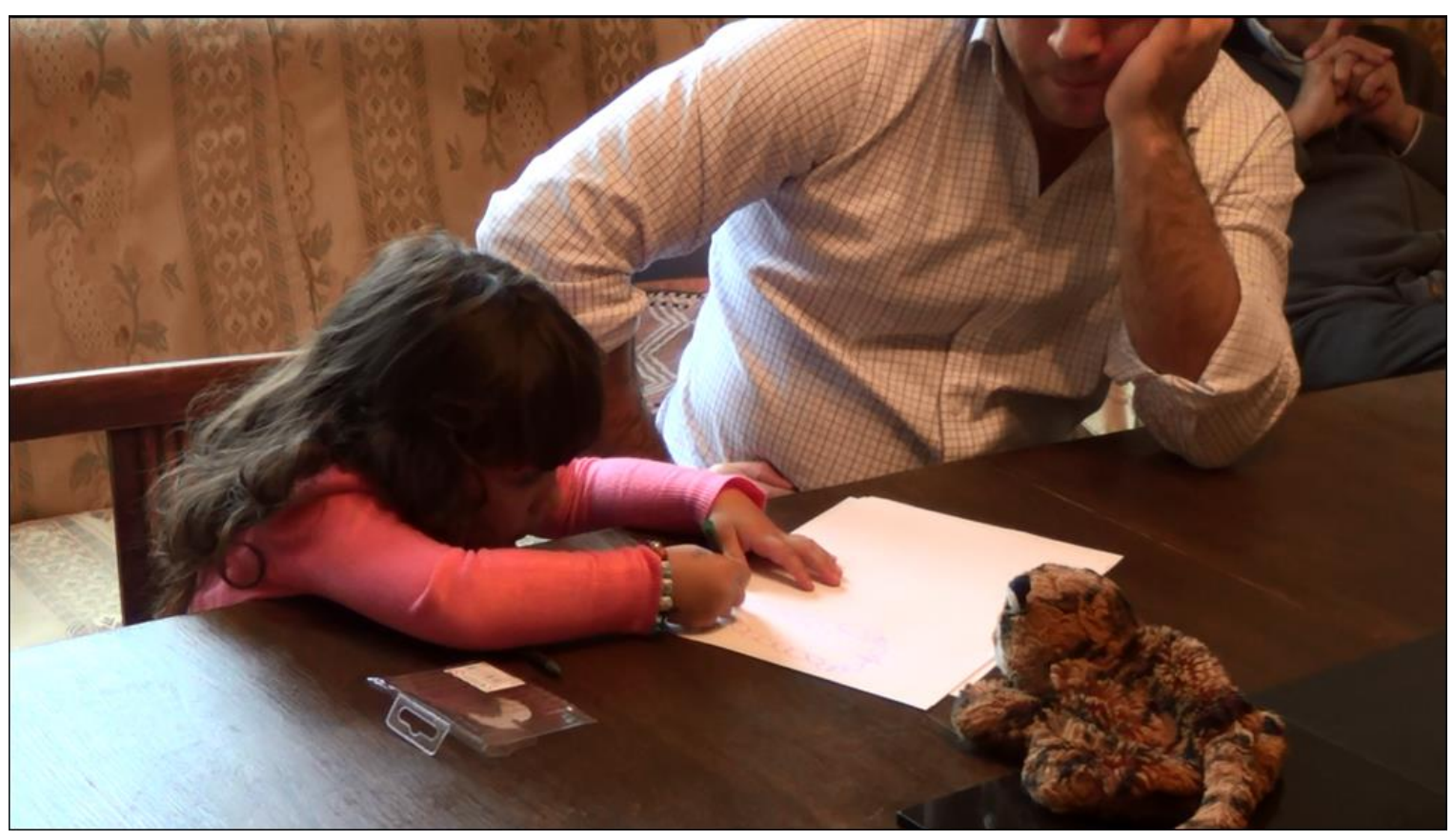


Figure2: Tuxpaint

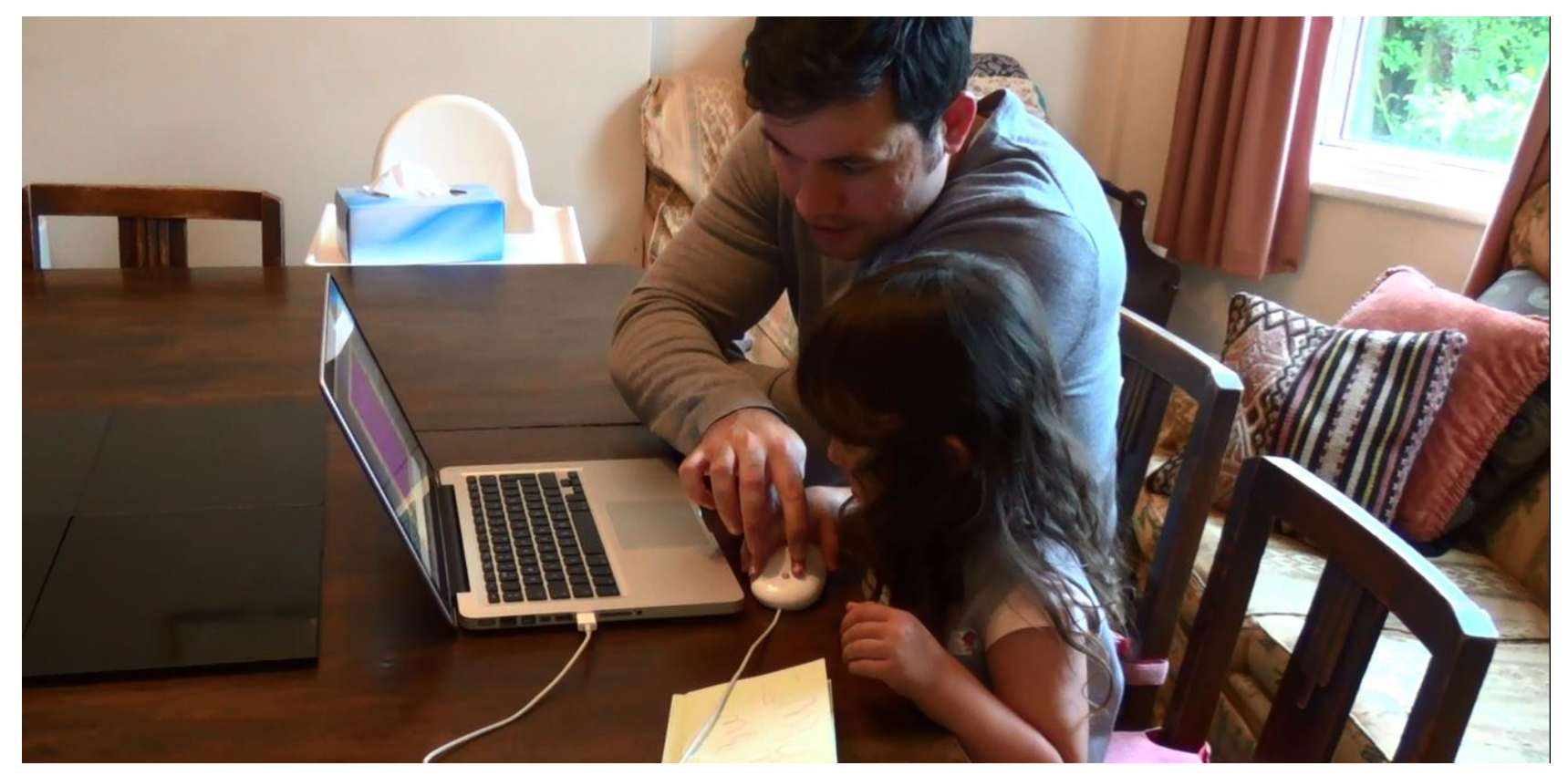


Figure3: Collage

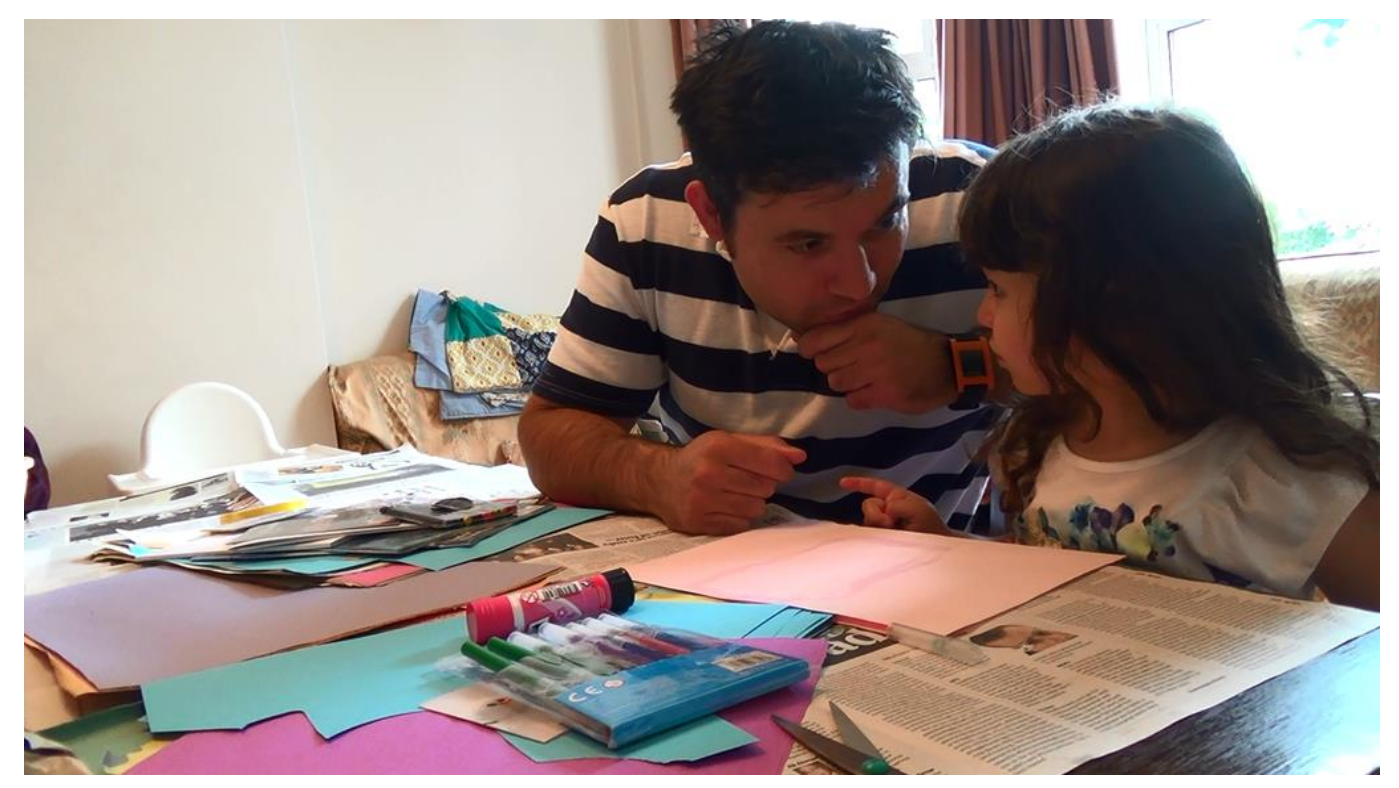


Figure4: iPad

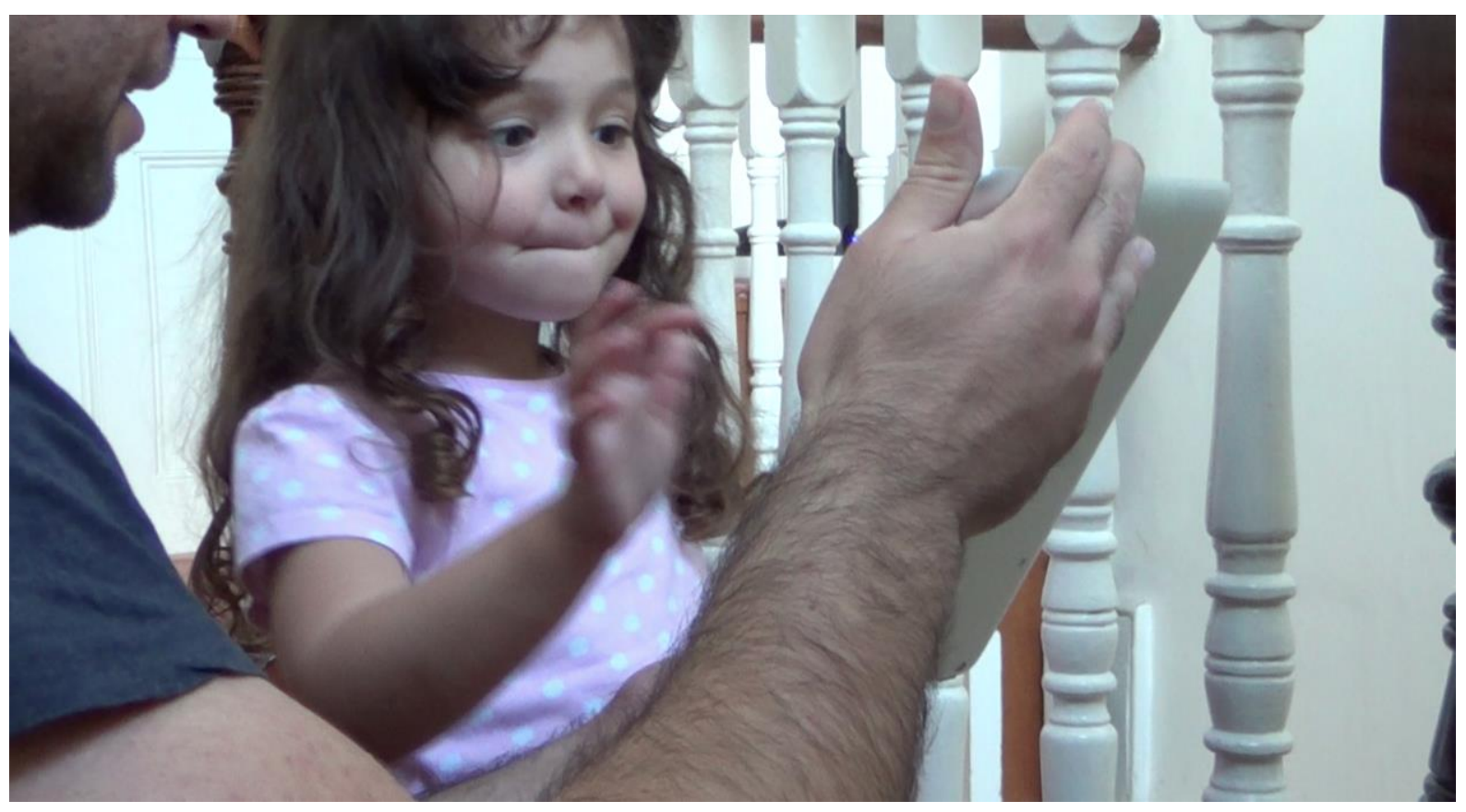


Figure5: Frequency of occurrence for the child's creativity categories coded

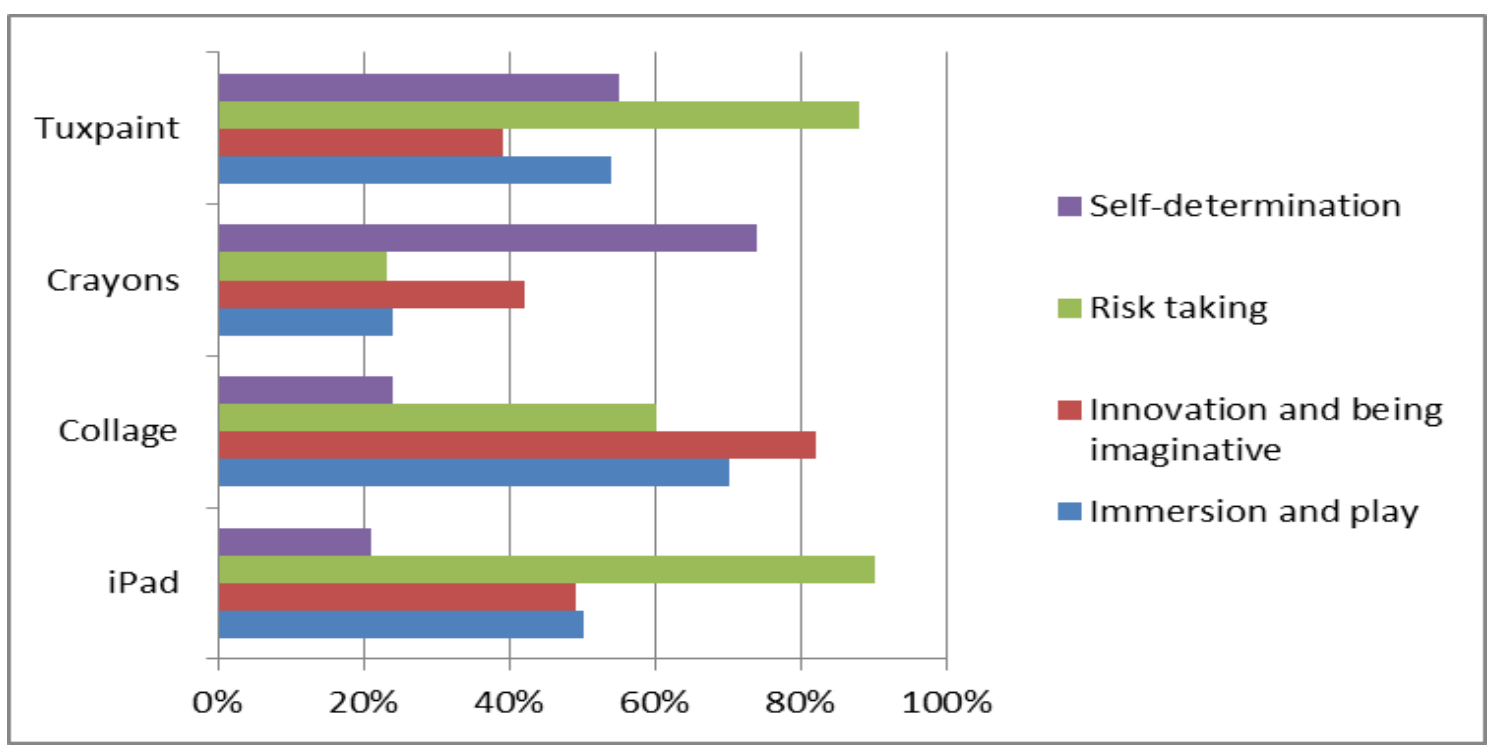


Figure6: Frequency of creativity facets supported by the father

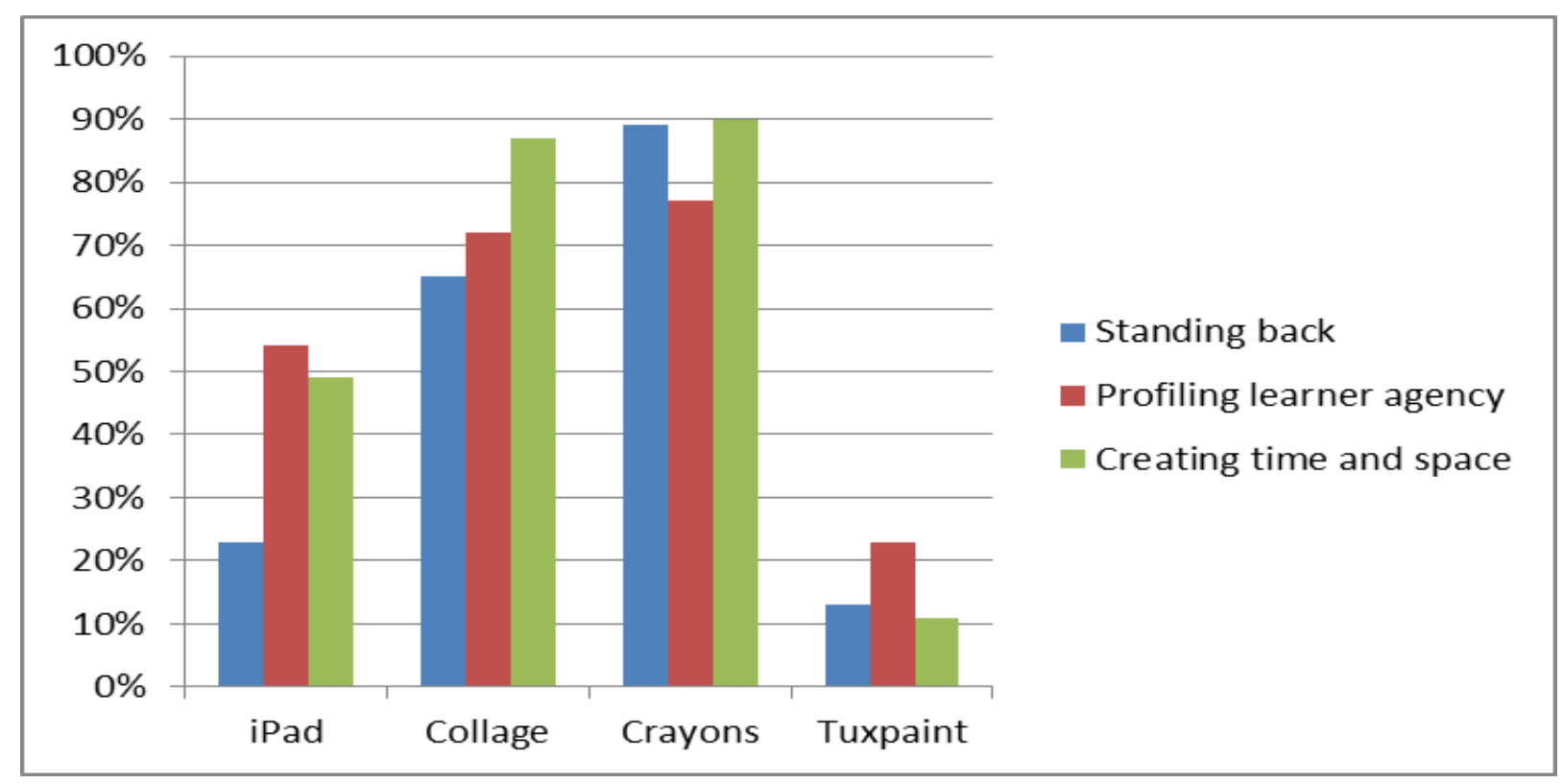


Figure7: Frequency of collaborative creativity

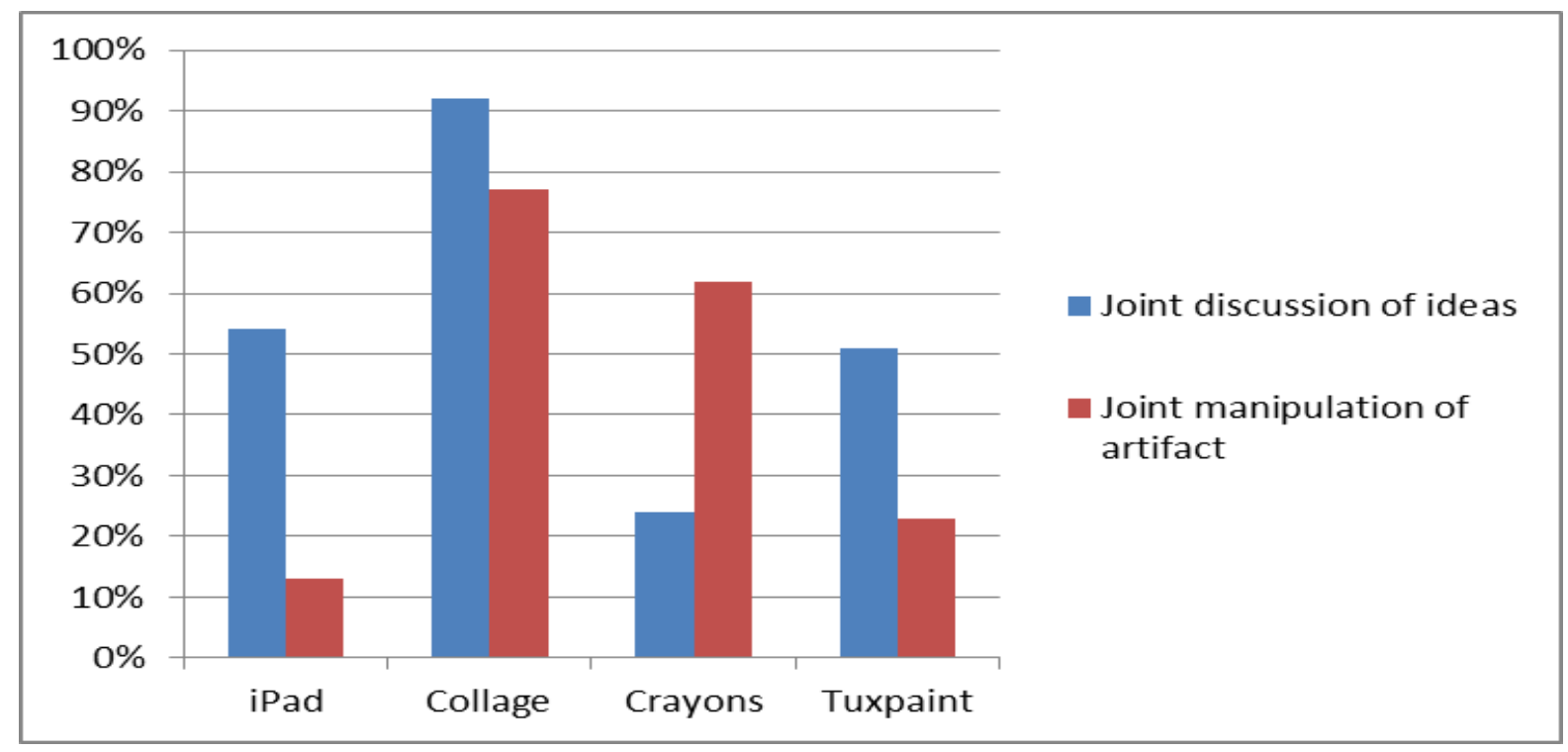


Figure8 : Artefacts produced
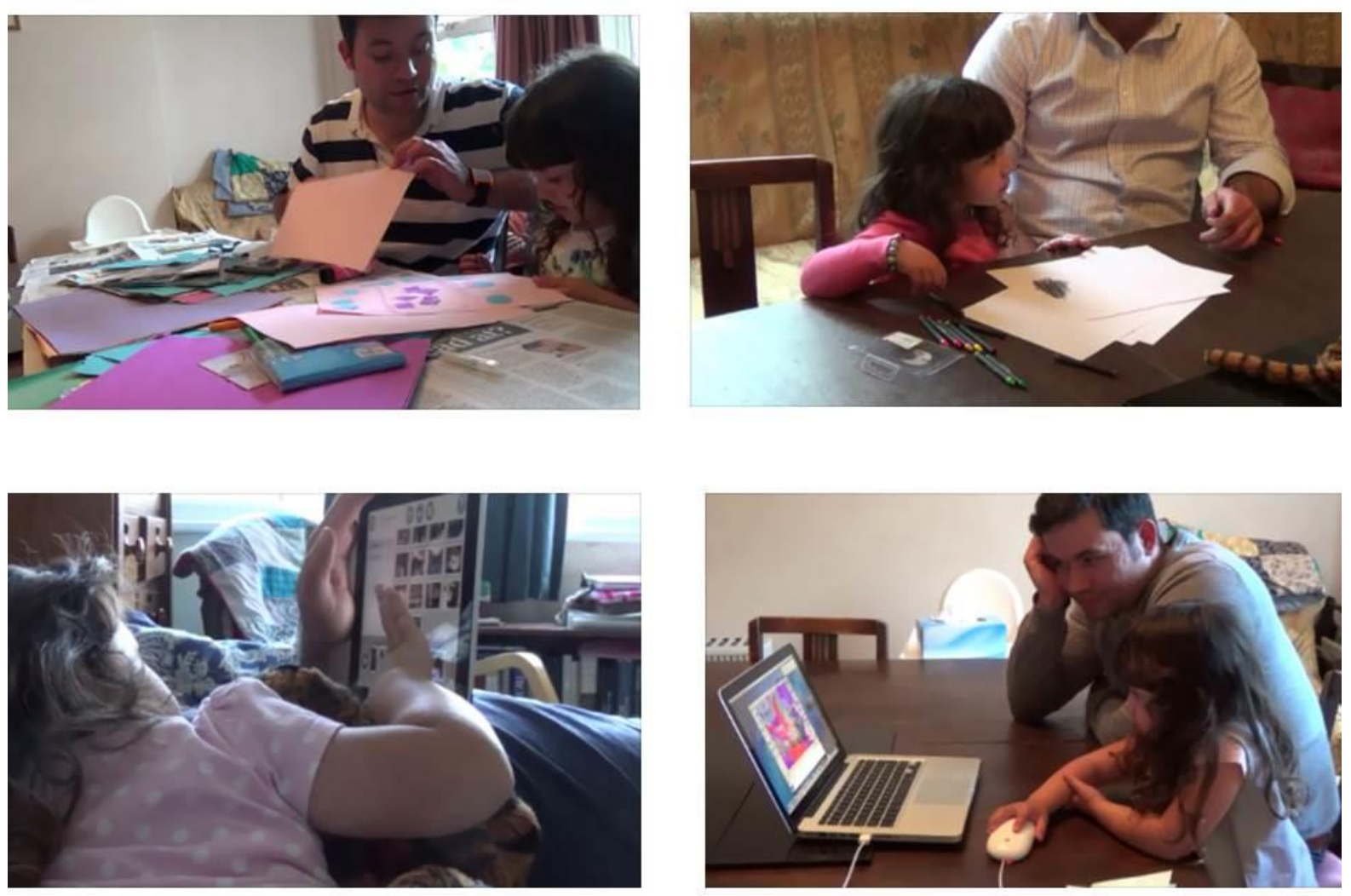